\title{
Parametric Theory of Cutoff Grade Estimation in Mining
}

\author{
B.K. Sahu \\ Professor Emeritus, Department of Earth Sciences, IIT BOMBAY, MUMBAI- 400076, India
}

Copyright $\mathrm{C} 2018$ by authors, all rights reserved. Authors agree that this article remains permanently open access under the terms of the Creative Commons Attribution License 4.0 International License

\begin{abstract}
Estimation of cutoff grade (fractional assay), $\mathrm{x}(\mathrm{C})$, in mining of mineral resources is crucial for profit maximization and sustainable growth $[7,8,9]$. It is very complex involving several geological and economic random variables which can be solved assuming the parameters are time-invariant (Static Models) or are time-varying (Dynamic Models). Parametric estimation of cutoff grade, $\mathrm{x}(\mathrm{C})$, involves modeling of the assay distribution of the ore (globally and locally) and of the economic random variables such as sale value of marketable ores (s/ton) and cost of production of mineral resource (c/ton). Fractional assay, $\mathrm{x}$ where $0<\mathrm{x}<1$, of minerals/oxides/elements in rocks and ores is known to possess globally/locally log-normal pdf or some log function of assay is Normal/Gaussian [1,3,4,6] under proper geological/statistical sampling, with the two parameters: $\operatorname{mean}(\mu)$ and variance $\left(\sigma^{2}\right)$. However, estimation of cutoff grade, $\mathrm{x}(\mathrm{C})$, where $(\mathrm{x}(\mathrm{C})=$ inverse cdf, $\left.\mathrm{F}^{-1}(\mathrm{x}(\mathrm{C}))\right)$, is a very complex problem for both static and dynamic modeling. A high cutoff induces lower profits as less ore material can be extracted for sale whereas a low cutoff also induces lower profits as a much larger quantity of lower grade ore and waste materials having little sale value have to be handled which increase the cost of mining and processing. Since life of mine is about 15 years or more all profits must be reduced to net present value (NPV) for economic comparisons and decisions [5]. Static model assumes time-invariant geological, spatial and economic random variables (rv.s) or random vectors needing simpler statistical analysis [4] to estimate the required parameters, whereas dynamic modeling though more realistic and desirable) requires rather complex time series analysis and forecasting procedure [3]. Forecasted values of the predictors from the concerned dynamic model parameters [3] are then used as inputs to the (linearized) regression equation in dynamic model situations. Optimal cutoff grade, $\mathrm{x}(\mathrm{CO})$, is therefore a time-step specific and/or block specific random variable which does not have a global value to be computed. Therefore, general solution to optimal grade, $\mathrm{x}(\mathrm{CO})$, under dynamic model is not feasible
\end{abstract}

and hence, not pursued further.

Keywords Cutoff Grade $\mathrm{x}(\mathrm{C})$, Optimal Cutoff Grade, $\mathrm{x}(\mathrm{CO})$, Break-even Grade with No Risk, x(B), Break-even Grade with Statistical Risk x(BR), Log-assay Statistical Parameters, Risk Analysis and Profit Optimization under Static/Dynamic Models

\section{Introduction}

Rapid rate of utilization of minerals and metals to maintain societal growth and current lifestyles, makes it imperative that leaner ores and ores from greater depths are to be extracted incurring much higher costs of mining and subsequent processing to make them marketable at profit. Hence, optimal extraction rate based on optimal cutoff grades is the urgent need of the hour for maximizing the profits with greater efficiency. In mining extraction of ores proceeds at two/three faces/blocks depending on demands and available labor and infrastructures. Rate of extraction must be profitable and bring sufficient cash flow for running the mine operations smoothly. Cutoff grade, $\mathrm{x}(\mathrm{C})$, of fractional assay, $\mathrm{x}$ where $0<\mathrm{x}<1$, plays a very important role as it determines the amount of marketable ores to be mined and blocks to leave in-situ as un-mined waste. Balance between growth targets and maintenance of ecology and environment are conflicting goals which is to be optimally and properly attained using suitable statistical methodology. Optimal cutoff grade, $\mathrm{x}(\mathrm{CO})$, yields maximum profits for each mined block and for each time-step of operation/accounting . Since, life of any large mine is usually 15 years or more, all these profits must be converted to net present value (NPV) using the standard economic formula: $\left(\mathrm{P}(\right.$ at $\left.\mathrm{t}=0)=\mathrm{P}(1+\mathrm{r})^{\wedge}-\mathrm{n}\right)$ where $\mathrm{r}$ is rate of interest/ inflation and $\mathrm{n}$ is the number of time-steps or years to reach present time, $\mathrm{t}=0$ or starting time for mining). Cutoff and optimal cutoff grades can be estimated using 
Static or Dynamic modeling techniques, where the input random variables are considered to be time-invariant or time-varying, respectively. For ores having a single mineral/element of economic value, fractional assays, $\mathrm{x}$, are scalar random variable, r.v., needing univariate statistical analysis, whereas if ores contain multiple minerals/elements of value; $x$, is a random vector needing multivariate statistical analysis. Estimation of cutoff grade, $x(C)$, and of optimal cutoff grade, $x(C O)$, is a very complex problem for geologist, mining engineer, financial consultants as well as even the mine owners to take good decision. A high cutoff value induces decrease in overall profits as extractable ore amount reduces, whereas a low cutoff value also induces decrease in profits as a larger proportion of un-marketable ores and wastes have to mined, processed and disposed off at considerable increased costs that reduces profits and may even induce loss.
Static models for estimating cutoff grade assume that the input geological and economic variables are time-invariant r.v.s and the resulting $\mathrm{x}(\mathrm{C})$ can be obtained by suitable inversion of cumulative distribution of $\mathrm{F}(\mathrm{x}(\mathrm{C})$ )(see, Tables 1-3). However, the inputs are truly time-varying r.v.s which are amenable to dynamic modeling and $\mathrm{x}(\mathrm{C})$ or $\mathrm{x}(\mathrm{CO})$ can be estimated by more complex time series modeling and forecasting methodology and subsequent inversion of $x(C)=F^{-1}(x(C))$ [3] and Eqn.9. The ore extraction rate must be optimized at each time-step of operation and for each block to be mined using $\mathrm{x}(\mathrm{CO})$ to maximize the overall profits. Dynamic models are the need of the hour for maximum profits as well as for conservation of non-renewable but finite mineral resources and for preserving the current fragile ecology and environment. Mining operations must follow National Mineral Policy, Mining Laws and other Government requirements for continued smooth mining operations.

Table 1. Feasible break-even grade, $x(B)$, and $x$ min or zero grade $<x(C) / x(C, O)$ assuming log-normal (log-Gaussian) pdf for ln $(x)$ with mean, $\mu$, and standard deviation, $\sigma$. Standardized random variable, $z$, can be calculated as $z=[\ln (x)-\mu] / \sigma$; hence we obtain, $x$ min $=E x p[\mu-\sigma$. $z$ min $]$ and $x$ max $=\operatorname{Exp}(\mu+\sigma . z$ max $)$. The values, $x(B)$ and $x \mathrm{~min} /$ zero grade, form the upper and lower bounds of cutoff grades, respectively. However, the upper bounds to $\mathrm{x}(\mathrm{C})$ given in Table 2 would be more useful, in practice, rather than those listed in Table1.

\begin{tabular}{ccccccc}
\hline (s/c) ratios & 1.15 & 10 & 100 & 1000 & 10000 & Remark \\
\hline $\mathrm{x}$ min or zero & 0.3 & 0.01 & 0.001 & 0.0001 & 0.00001 & Lower Bound \\
\hline $\mathrm{F}(\mathrm{x}(\mathrm{B}))$ & 0.84 & 0.99 & 0.999 & 0.9999 & 0.99999 & Upper Bound \\
\hline
\end{tabular}

Table 2. Values of upper bounds, $\mathrm{F}(\mathrm{x}(\mathrm{B}))$ ), and lower bounds, $\mathrm{x}$ (min) or Zero, to the cutoff grade, $\mathrm{F}(\mathrm{x}(\mathrm{C})$ ), for different economically feasible (s/c) ratios, greater than 1.0, as obtained by Eqn.(2).

\begin{tabular}{ccccccccc}
\hline $\mathrm{x}$ & 1 & 2 & 3 & 4 & 5 & 6 & 10 & Remarks \\
\hline $\mathrm{F}(\mathrm{x}(\mathrm{B}))$ & 1 & 0.5 & 0.33 & 0.25 & 0.2 & 0.167 & 0.100 & Upper Bound \\
\hline $\mathrm{F}(\mathrm{x}(\mathrm{C}))$ & 0 & 0 & 0 & 0 & 0 & 0 & 0 & Lower Bound \\
\hline
\end{tabular}


Table 3. Fractional cutoff grade (assay), $x(C)$, for different ratios of sales to cost prices, (s/c) ratios, and corresponding fractional-break even grade, $\mathrm{F}(\mathrm{x}(\mathrm{B})$ ), as calculated by Equation 3 in this Table 3. Beyond $(\mathrm{s} / \mathrm{c})$ ratio of 2.0, the $\mathrm{F}(\mathrm{x}(\mathrm{C})$ ) values will be essentially $\mathrm{x}$ (minimum) or Zero; hence has not been given in this table. The optimal cutoff grade (as given by Eqn.6), $\mathrm{F}(\mathrm{x}(\mathrm{CO})$ ), lies between $\mathrm{F}(\mathrm{x}(\mathrm{min}) / \mathrm{zero})$ and $\mathrm{F}(\mathrm{x}(\mathrm{B}))$ values

\begin{tabular}{|c|c|c|c|c|c|c|c|c|c|c|c|c|}
\hline $\begin{array}{c}(\mathbf{s} / \mathbf{c}) \\
\mathbf{F}(\mathbf{x}(\mathbf{B}))\end{array}$ & 1.0 & 1.1 & 1.2 & 1.25 & 1.3 & 1.4 & 1.5 & 1.6 & 1.7 & 1.8 & 1.9 & 2.0 \\
\hline .005 & .005 & & & & & & & & & & & \\
\hline .010 & .010 & & & & & & & & & & & \\
\hline .015 & .015 & & & & & & & & & & & \\
\hline .020 & .020 & & & & & & & & & & & \\
\hline .025 & .025 & & & & & & & & & & & \\
\hline .030 & .030 & & & & & & & & & & & \\
\hline .035 & .035 & & & & & & & & & & & \\
\hline .040 & .040 & & & & & & & & & & & \\
\hline .045 & .045 & .000 & & & & & & & & & & \\
\hline .050 & .050 & .000 & 0 & & & & & & & & & \\
\hline .100 & .100 & .010 & 0 & 0 & & & & & & & & \\
\hline .150 & .150 & .070 & 0 & 0 & 0 & & & & & & & \\
\hline .200 & .200 & .120 & .040 & 0 & 0 & 0 & & & & & & \\
\hline .250 & .250 & .175 & .100 & .060 & .025 & 0 & 0 & & & & & \\
\hline .300 & .300 & .230 & .160 & .120 & .090 & .020 & 0 & 0 & & & & \\
\hline .350 & .350 & .285 & .220 & .190 & .145 & .070 & .025 & 0 & 0 & 0 & & \\
\hline .400 & .400 & .340 & .280 & .250 & .220 & .160 & .010 & .040 & 0 & 0 & 0 & 0 \\
\hline .450 & .450 & .395 & .340 & .310 & .285 & .230 & .175 & .120 & .065 & .010 & 0 & 0 \\
\hline .500 & .500 & .450 & .400 & .370 & .350 & .300 & .250 & .200 & .150 & .100 & .050 & 0 \\
\hline .600 & .600 & .340 & .280 & .250 & .220 & .160 & .100 & .040 & $\mathrm{x}$ & $\mathrm{x}$ & $\mathrm{x}$ & $\mathrm{x}$ \\
\hline .700 & .700 & .230 & .160 & .125 & .090 & .020 & $\mathrm{x}$ & $\mathrm{x}$ & $\mathrm{x}$ & $\mathrm{x}$ & $\mathrm{x}$ & $\mathrm{x}$ \\
\hline .800 & .800 & .120 & .040 & $\mathrm{x}$ & $x$ & $x$ & $\mathrm{x}$ & $\mathrm{x}$ & $\mathrm{x}$ & $\mathrm{x}$ & $\mathrm{x}$ & $\mathrm{x}$ \\
\hline .900 & .900 & .010 & $\mathrm{x}$ & $\mathrm{x}$ & $\mathrm{x}$ & $\mathrm{x}$ & $\mathrm{x}$ & $\mathrm{x}$ & $\mathrm{x}$ & $\mathrm{x}$ & $\mathrm{x}$ & $\mathrm{x}$ \\
\hline 1.00 & 1.00 & $\mathrm{x}$ & $\mathrm{x}$ & $\mathrm{x}$ & $\mathrm{x}$ & $\mathrm{x}$ & $\mathrm{x}$ & $\mathrm{x}$ & $\mathrm{x}$ & $\mathrm{x}$ & $\mathrm{x}$ & $\mathrm{x}$ \\
\hline
\end{tabular}




\section{Static Modelling}

Mineral resources are materials having higher concentrations of minerals/elements compared to their concentrations in crustal rocks, whereas ore deposit is a mineral resource with significantly higher concentrations of these minerals/elements to make the extractable and marketable at profit. Ore deposit must have sufficient amount of resources (W) so that mine can operate economically for considerable length of time (mine life, say 15 or more years). Mineral resources are characterized by their unique geological setting and genesis, as well as their spatial distribution which greatly influence their optimal extraction rate. Sustainable mining operations consist of continued profit accruals for the mine-life by extraction of marketable ores or marketable blended and/or beneficiated ores; which imply sale price (s/ton) is greater than production cost (c/ton). Production costs include: mining, blending, beneficiating, transportation, treatment and disposal of mine wastes, etc. These are really time-varying but can be controlled by management. However, sale price(s/ton) is not controlled by mine managers and is highly volatile time-varying random variables due to unpredictable demand/supply/competition, government policies, technical innovations, substitute availability, mine management policies, etc.

The optimal cutoff grade, $x(\mathrm{CO})$, lies in between the upper bound, break-even grade, $\mathrm{x}(\mathrm{B})$ (no Statistical Risk) or $\mathrm{x}(\mathrm{BR}$ with appropriate statistical RISK), and the lower bound (High Risk), x min or zero assay value. Under static model, the optimal cutoff grade, $\mathrm{x}(\mathrm{CO})$, can be estimated using two factors: pdf of assays, $x$ and the (non-Gaussian) ratio of sale price to production cost $(\mathrm{s} / \mathrm{c})$. Under dynamic model, however, these parameters are truly time-varying and block-varying and hence, $\mathrm{x}(\mathrm{CO})$, must be estimated for each time-step/accounting or for blocks of mining operations/accounting using the standard time series and forecasting methods separately for sales and costs sequence equal-interval data as detailed in the book [3].

Characteristics of probability density function (pdf) for fractional assays, $\mathrm{x}(0<\mathrm{x}<1)$, in ore body can be obtained by measuring a large number $(\mathrm{N}>50$ or more) of independent representative volume (REV) [2] samples/cells/blocks collected in 3D space. From these measurements, graphical and moment statistics of fractional assay, $\mathrm{x}$, can be obtained using standard statistical methods. However, it is well known that fractional assay follow a pdf/cdf that is log-Normal $[1,3,4,6]$ and hence, such statistics should be computed on $\ln (\mathrm{x}) /$ $\log (\mathrm{x})$ or suitable NORMALIZED log-transformed fractional assay, as the r.v. to obtain the parameters needed such as log-normalized mean (u) and log-normalized standard deviation $(\sigma)$ by using statistical methods on $\ln (\mathrm{x})$ or normalized log-transformed(x), as inputs (or else, arithmetic moments computed on assay (x) can be transformed to obtain their log-Normal parameters $\mathrm{u}(=$ $\ln ($ median of $\mathrm{x}))$ and $\sigma[4,6]$. These $\ln (\mathrm{x})$ parameters are used for estimating $\mathrm{x}(\mathrm{C})$ and $\mathrm{x}(\mathrm{CO})$ [8.9]. Break-even grade, $\mathrm{x}(\mathrm{B})$, is very important for extraction as it demarcates assays that are marketable $(x>x(B))$ with profit (such that average arithmetic assay of extracted and marketable ores (av. $x$ ) is greater than marketable grade $\mathrm{x}(\mathrm{M})$ ) from assays that forms lean ores and not marketable $(\mathrm{x}<\mathrm{x}(\mathrm{B}))$. Thus, we obtain:

$$
\begin{gathered}
(1-\mathrm{F}(\mathrm{x}(\mathrm{B}))) \mathrm{s}=\mathrm{c} ; \\
\text { or, } \mathrm{F}(\mathrm{x}(\mathrm{B}))=(1-(\mathrm{c} / \mathrm{s})) .
\end{gathered}
$$

At some cutoff grade, $x(C)>0$ (or, $x$ min), we similarly obtain:

$$
\begin{aligned}
& (1-\mathrm{F}(\mathrm{x}(\mathrm{B}))) \mathrm{s}=(1-\mathrm{F}(\mathrm{x}(\mathrm{C}))) \mathrm{c}, \\
& \text { or, } \mathrm{F}(\mathrm{x}(\mathrm{B}))=1-(1-\mathrm{F}((\mathrm{x}(\mathrm{C})))(\mathrm{c} / \mathrm{s}) .
\end{aligned}
$$

Reversing Eqn.2, we can obtain

$$
\mathrm{F}(\mathrm{x}(\mathrm{C})) \text { as: } \mathrm{F}(\mathrm{x}(\mathrm{C}))=1-(1-\mathrm{F}(\mathrm{x}(\mathrm{B})))(\mathrm{s} / \mathrm{c}) \text {. }
$$

Eqns. 1,2,3 are nonlinear equations and it would be prudent to obtain their equivalent Linearized versions by taking proper log-transforms on LHS (Criterion) and RHS (Regressor) terms and including the error terms (e(i)s, as for example:

$$
\begin{gathered}
\ln (1-\mathrm{F}(\mathrm{x}(\mathrm{C})))=\ln (1-\mathrm{F}(\mathrm{x}(\mathrm{B})))+ \\
+\ln (\mathrm{s})-\ln (\mathrm{c})+\mathrm{e}(1)+\mathrm{e}(2)+\mathrm{e}(3),
\end{gathered}
$$

where, e(i)s are error terms of the linear regression equation corresponding to first, second and third random variables in the RHS of equation (3). Eqn(3A) would be useful in static and dynamic modeling.

Equation (3) shows that $\mathrm{F}(\mathrm{x}(\mathrm{B}))$ forms the upper bound to cutoff grade, $\mathrm{F}(\mathrm{x}(\mathrm{C}))$, and if for break-even grade, $\mathrm{x}(\mathrm{B})$, $(\mathrm{s} / \mathrm{c})$ or $(\mathrm{c} / \mathrm{s})=1$, then $\mathrm{F}(\mathrm{x}(\mathrm{C}))=\mathrm{F}(\mathrm{x}(\mathrm{B}))$, (No risk solution; Table 1). The lower bound to $F(x(C))$ is obviously $F(x$ $\mathrm{min} /$ zero assay value $)$ ) and corresponding $\mathrm{x}(\mathrm{C})$ or $\mathrm{x}(\mathrm{B})$ can be obtained by inversion of Fs (as $F^{-} 1$ ) using $\log$-Normal pdf of $\mathrm{x}$ as : $\mathrm{x}(\mathrm{min})=\operatorname{Exp}(\mu-3 \sigma)][9,10](\mathrm{see}$, Tables 1 and 2 which provide upper and lower bounds of $\mathrm{F}(\mathrm{x}(\mathrm{C})$ at different $(\mathrm{s} / \mathrm{c})$ ratios $)$.

Geologists and mining engineers have been using cutoff grade by empirically estimating their values by trial-and-error methods which is tedious and not very scientific as pdf information $(\ln (\mathrm{x})$ or equivalent Normalized log-transformed $\mathrm{x}$ ) which is NORMAL/GAUSSIAN), was NOT used. Optimal cutoff grade, $\mathrm{x}(\mathrm{CO})$, will lie between these two upper bound $(\mathrm{x}(\mathrm{B}))$ and lower bound $\mathrm{x}(\mathrm{C})$ of fractional assay $\mathrm{F}(\mathrm{x}(\mathrm{C}))$, as determined from Eqn. 3 for different profitable $(\mathrm{s} / \mathrm{c})$ ratios with corresponding compliment of break-even grade, that is $1-\mathrm{F}(\mathrm{x}(\mathrm{B}))$, which can be used as guideline to obtain $\mathrm{F}^{\wedge}-1(\mathrm{x}(\mathrm{C}))$. We would prefer to use $\mathrm{F}(\mathrm{x}(\mathrm{C}))$ as near the lower bound so that a larger proportion of ore material is extracted and marketed.

Geologists and mining engineers have been using cutoff 
grade, $\mathrm{x}(\mathrm{C})$, determined empirically or by trial-and-error methods which are rather tedious and of less scientific value since the probability density function (pdf) assay values in ores is NOT used at all. Optimal cutoff grade, $\mathrm{x}(\mathrm{CO})$, will lie between the the upper and lower bounds ( $\mathrm{x}$ $\mathrm{min}$ ) as listed in Table 2. In practice, it would be prudent to use the upper bound in Table 2 and the lower bound in Table 1. Optimal cutoff grade, $x(\mathrm{CO})$, lies in between these two bounds for Static Models. Table 3 lists more accurate values of $\mathrm{F}(\mathrm{x}(\mathrm{C}))$ as determined by Equation 3 for different values profitable $(\mathrm{s} / \mathrm{c})$ ratios $(>1.0)$, for corresponding cdf of break-even point, $\mathrm{F}(\mathrm{x}(\mathrm{B}))$, that can be used to compute $x(C)$ by inversion of the $\operatorname{cdf} F(x(C))$ which is NORMAL/GAUSSIAN with suitable $\log$-transformation (such as $\log (\mathrm{x} /(1-\mathrm{x})$ ) for major and $\log (\mathrm{x})$ for trace elements $[3,4,5]$ of fractional assay values, $\mathrm{x}$, in the ores.

Profit occurs when sale price $(\mathrm{s} / \mathrm{ton})$ of marketed ore exceeds the production cost (c/ton) of mined resource. Thus, we have:

$$
(1-\mathrm{F}(\mathrm{x}(\mathrm{B}))) \mathrm{s}>\mathrm{c} .
$$

Total profit using a cutoff grade, $\mathrm{F}(\mathrm{x}(\mathrm{C}))$, is then:

$$
\mathrm{P}=\mathrm{W}(1-\mathrm{z}(\mathrm{x}(\mathrm{C})))(\mathrm{s}-\mathrm{c})
$$

where, $\mathrm{z}(\mathrm{x}(\mathrm{C}))$ is standardized value of $\mathrm{x}(\mathrm{C})$ that is $(\ln (\mathrm{x})$ $\mu) /(\sigma)=z$ and $f(z)$ is unit Normal, $n(0,1)$, and $W$ is the total extractable mineral resource. Eqn. 5 is non-linear, and it would be prudent to use an equivalent Linear equation by taking its $\ln$ - transform using $\mathrm{x}(\mathrm{CO})$ instead of $\mathrm{x}(\mathrm{C})$ as:

$$
\ln (\mathrm{P})=\ln (\mathrm{W})+\ln (1-\mathrm{z}(\mathrm{x}(\mathrm{CO})))+\ln (\mathrm{s}-\mathrm{c}) \text {. }
$$

For static model, we can mine material with assay less than $\mathrm{x}(\mathrm{B})$ as this has much more sale value(s/ton) compared to cost of production (c/ton) This is called Risk analysis in statistics [see, 4,8,9]. Then, break-even grade with Risk becomes, $x(B R)$, which can be calculated using unit Normal transformation to $\ln (\mathrm{x})$, i.e., $\mathrm{z}=\mathrm{n}(0,1)$ for the r.v., $(\ln x-\mu) /(\sigma)$. Using cumulative unit normal $\mathrm{N}(0,1)$ tables for various $\mathrm{z}$ values, we get $[8,9]$ :

$$
[\mathrm{N}(\mathrm{z}(\mathrm{x}(\mathrm{BR})))-\mathrm{N}(\mathrm{z}(\mathrm{x}(\mathrm{B})))] /[\mathrm{N}(\mathrm{z}(\mathrm{x}(\mathrm{B})))-\mathrm{N}(\mathrm{z}(-\infty)))]=(\mathrm{c} / \mathrm{s}),
$$

Compare Eqn. 6 with the Eqn.,1, for determination of $x(B)$. From Eqn. 6, the value of $z(x(B R))$ is calculated and transformed to equivalent $x(B R)$ at mine office. For static model, $x(B R)$, may be close to or equivalent to optimal cutoff grade, $x(\mathrm{CO})$, but this can really be checked by independently computing for $\mathrm{x}(\mathrm{CO})$ using several trial-and- error solution to optimize profits.

For dynamic model, the value of $\mathrm{x}(\mathrm{CO})$ is frequently needed at each time-step or block to be mined, and hence, Eqn. 6 should be programmed after replacing in its value $\mathrm{x}(\mathrm{BR})$ by $\mathrm{x}(\mathrm{CO})$ as is desired, to obtain the value of $\mathrm{x}(\mathrm{CO})$ as and when it is needed for each time-step and for each block that is mined.

\section{Dynamic Modelling}

In dynamic modeling, the geological and economic random variables used to estimate the cutoff grade, $\mathrm{x}(\mathrm{C})$ or the optimal cutoff grade, $x(\mathrm{CO})$ are assumed to be time-varying which are realistic assumptions and therefore, yields maximum profits during the entire lifetime of the mine operations. Hence, mining operations are discretized into equal interval time-steps (say, 1,3, or 6 months) as is desired for accounting, updating and forecasting purposes. Also, each block of ore to be mined should be analyzed to obtain optimal cutoff grade for maximum profit at that time (say using Eqn.6). The value of $\mathrm{x}(\mathrm{CO})$ would lie between $\mathrm{x}$ min(HIGH RISK) and $x(B R)$ (Statistically acceptable RISK yields $x(B R)$ which is less than $x(B)$ ).

Dynamic modeling for estimating optimal cutoff grade, $\mathrm{x}(\mathrm{CO})$, involves several steps [see,10]:

(i). Linearize the cutoff grade equation (3A) by taking log-transformed Regression equation as:

$$
\begin{gathered}
\ln (1-\mathrm{x}(\mathrm{CO}))=\ln (1-\mathrm{x}(\mathrm{BR}) \text { or } \mathrm{X}(\mathrm{B}))+\ln (\mathrm{s})-\ln (\mathrm{c})+ \\
\mathrm{e}(1)+\mathrm{e}(2)+\mathrm{e}(3),
\end{gathered}
$$

where, error terms e $(\mathrm{i}), \mathrm{i}=1,2,3$, refer to the three predictors on RHS of Eqn(3A). Values of each predictor can be forecasted for the concerned time-step by $\operatorname{ARIMA}(\mathrm{p}, \mathrm{d}, \mathrm{q})$ time series techniques detailed in [3] which also give estimates of error variances of e(i) as needed for forecasted confidence limits( say at 5\% level). Then, the predicted value of $\ln (1-\mathrm{F}(\mathrm{x}(\mathrm{CO})))$ with its confidence limits can be easily obtained.

(ii). Usually the time series may possess linear trend (economic growth) which can be eliminated by differencing the sequence once and then modeling the differenced sequence as stationary $\operatorname{ARMA}(p, q)$ process where $\mathrm{d}$ is taken as 1 (local stationarity). Sum predicted sequence once to get original sequence.

(iii) The predicted value of $\ln (1-\mathrm{x}(\mathrm{CO}))$ can then be inverted to obtain $\mathrm{x}(\mathrm{CO})$ as $\mathrm{x}(\mathrm{CO})=\mathrm{EXP}[1-$ predicted value of $\ln (\mathrm{x}(\mathrm{CO}))]$. This process is repeated to obtain the upper and lower confidence limits as well as for a few lead steps as seems necessary.

(iv) The above- mentioned steps are followed for each ore block to be mined as well.

The main difficulties in such time series modeling are there can be Governmental Policy Change yielding Intervention Type models, or market volatility due to drastic changes in demand and supply of ores, or due to introduction of high impact technology, or by sudden substitution activity, etc. However, since $\mathrm{x}(\mathrm{CO})=$ $\mathrm{F}^{-1}(\mathrm{x}(\mathrm{CO}))=\mathrm{N}^{-1}(\mathrm{z}(\mathrm{CO}))$ values are time-step specific and block specific, it is not possible to provide general global values for $\mathrm{x}(\mathrm{C})$ or $\mathrm{x}(\mathrm{CO})$ as was done in static models. If the assay distribution is $\log$-normal, $\ln (\mathrm{x})=\mathrm{n}\left(\mu, \sigma^{2}\right)$, then $\mathrm{z}(\mathrm{CO})$ becomes $\{\ln (\mathrm{x}(\mathrm{CO})-\mu) /(\sigma)\}$ and the standard unit Normal Probability/Cumulative probability Tables can used for the solution to $\mathrm{x}(\mathrm{CO})$. 
In large mines, ore blending and/or ore benefaction processes are normally routinely performed in order to upgrade the lean ores to marketable grades and by-products which often insures additional profits and this also solves waste utilization/disposal problems to a large extent thereby increasing sustainability of the mine as well as protecting the ecology and environment. Dynamic modeling of extraction of ores is recommended for maximization of profits in any large mining operation.

\section{Procedure Using Marketable Grade, $\mathrm{x}(\mathrm{M})$, As Input Random Variable}

The procedures in Section III for obtaining cutoff/optimal cutoff grades, $(\mathrm{x}(\mathrm{C}) / \mathrm{x}(\mathrm{CO}))$, unfortunately depends accurate knowledge of break-even grade, $\mathrm{x}(\mathrm{B})$ for a specific mineral/element of interest, which is usually unknown and depends on many geological and economic random variables. It is well known that $\mathrm{x}(\mathrm{B})$ is seldom globally stationary( or constant) as in highly dependent of heterogeneities of the resource in 3D space and also temporally as market sale value is rather volatile in short-terms and the cost of production also fluctuates (though perhaps less volatile compared to sale value). Here e develop a theory of estimating $\mathrm{x}(\mathrm{C}) / \mathrm{x}(\mathrm{CO})$ locally(NOT GLOBALLY) in terms of only the economic random variables inducing market sale price(s/ton). By $\sim$ LOCALLY we mean it is applicable for short time periods (say, 1,3,6 months as desired) and for individual, (NOT necessarily the whole face), Blocks/Faces/Pillars where mining operations are continued. This procedure has advantage of knowing $\mathrm{x}(\mathrm{M})$ exactly for the given time period of interest and analysis. The main idea is that the average grade of ore mined from any Block/Face/Pillar must be greater or at least equal to the marketable grade, $\mathrm{x}(\mathrm{M})$. Again, we assume that in smaller space domains such as Block/Face/Pillar is more homogeneous and the assay distribution of ore is log-normal but its mean and variance/standard deviation (mean $\mu, \sigma^{2} / \sigma$ on $\ln (\mathrm{x}) / \lg (\mathrm{x})$ basis) is locally constant but not necessarily globally applicable (as was done in Section III). If a cutoff grade $\mathrm{x}(\mathrm{C})$ is used to mine resources having assays above this grade $(>x(C))$, then the arithmetic mean assay of mined materials (according to log-normal distribution of assay values $\mathrm{z}(\mathrm{x}(\mathrm{M}))=(\ln (\mathrm{x}(\mathrm{M})-\mu) / \sigma)$ should be equal to $\mathrm{x}(\mathrm{M})$ and thus we obtain:

$$
\begin{gathered}
\text { or, }\left(1-\mathrm{F}(\mathrm{x}(\mathrm{C})) \cdot \exp \left(\mu+1 / 2 \sigma^{2}\right)=\mathrm{x}(\mathrm{M})=\operatorname{Exp}\left(\mathrm { z } \left(\mathrm{x}(\mathrm{M}) \cdot \sigma^{+}\right.\right.\right. \\
\mu), \\
\text { or, } \mathrm{F}(\mathrm{x}(\mathrm{C}))=1-\exp \left(\mathrm{z}(\mathrm{x}(\mathrm{M})) \cdot \sigma-1 / 2 \sigma^{2}\right) . \\
\text { Inverting } \left.\mathrm{F}(\mathrm{x}(\mathrm{C})) \text {, we get: } \mathrm{x}(\mathrm{C})=\mathrm{F}^{-1}(\mathrm{x}(\mathrm{C}))=\mathrm{x}(\mathrm{C})\right)= \\
\mathrm{N}^{-1} \\
\left\{1-\operatorname{Exp}\left(\mathrm{z}(\mathrm{x}(\mathrm{M})) \cdot \sigma-1 / 2 \sigma^{2}\right\} .\right.
\end{gathered}
$$

Unfortunately, we cannot easily obtain entries of $x(C)$ similar to those of $\mathrm{F}(\mathrm{x}(\mathrm{C})$ values as in Table 3 .
Linearizing Eqn(7), we obtain:

$$
\ln (1-\mathrm{F}(\mathrm{x}(\mathrm{C}))=\mu+\mathrm{z}(\mathrm{x}(\mathrm{M})) \cdot \sigma,
$$

which, can be used to regress the criterion $\ln (1-\mathrm{F}(\mathrm{x}(\mathrm{C}))$ against local values of mean $\mu$ and the (nonlinear) product $\sigma . z(x(M))$, if required. To insure that marketed ores are not rejected by the purchaser because of sampling errors due to random sampling of a few Lots of bulk ore materials, we can use a safer value of $1.02 \times(\mathrm{M})$, ( which is $2 \%$ greater than the marketable grade $x(M)$ ), instead of $x(M)$ in the analysis given in Section IV.

\section{Conclusions}

(i). Cutoff grade (fractional assay) in minerals resources, $\mathrm{x}(\mathrm{C})$, involves many complexly interrelated geological; spatial distributional; probability density function (pdf), $(\ln (x)$ is known to be Gaussian; and highly volatile economic factors such as sale price (s/ton) and production cost (c/ton). Cutoff grade is greatly important in mining as it determines decision on blocks of value to mine for profits or to be left in situ without mining as waste thereby saving mining cost (see, Tables 1-3 for guideline).

(ii). Cutoff grade, $x(C)=F^{-1}(x(C))$, is a random variable which should be estimated for each mineable block and for each time-interval of operation/accounting. Static modeling assumes these random variables are time-invariant which yields simpler solutions (Eqns. 3/3A). Dynamic modeling are realistic yielding better profits but their solution include complex time series modeling and forecasting as the inputs are time-varying random variables/ random vectors (Eqn.7).

(iii). Optimal cutoff grade, $\mathrm{x}(\mathrm{CO})=\mathrm{F}^{-1}(\mathrm{x}(\mathrm{CO}))$, yielding maximum profits in any time-step and/or for any block, lies in the range: minimum grade to breakeven grade (without ( $\mathrm{x}(\mathrm{B})$ or with statistical risk, $\mathrm{x}(\mathrm{BR})$ ). Minimum grade, $\mathrm{x}$ min, can be estimated as $\operatorname{Exp}[\mu-3(\sigma)]$, where the mean and standard deviation $(\sigma)$ can be calculated on $\ln (\mathrm{x})$ pdf being Normal/Gaussian. Break-even grade, $\mathrm{x}(\mathrm{B})=\mathrm{F}^{-1}(\mathrm{x}(\mathrm{B}))$, depends on the ratio (c/s) Eqn.1) and $\mathrm{x}(\mathrm{BR})$ can be estimated as in Eqn.6 and this value may be actually the same as the desired $\mathrm{x}(\mathrm{CO})$.

(iv). Optimal cutoff grade, $x(\mathrm{CO})$, is to be estimated for each mineable block and for each time-step of operation/accounting under dynamic modeling approach in order to maximize the overall profits. Dynamic models for estimation of $\mathrm{x}(\mathrm{CO})$ is necessary and recommended for mining precious metals and gemstones such as $\mathrm{Pt}, \mathrm{Au}, \mathrm{REE}$, $\mathrm{U}$ and Diamonds, these minerals possess extremely volatile sale values.

(v) Using the marketable grade $\mathrm{x}(\mathrm{M})$ which is more accurately known for short-time intervals or for local blocks/faces/pillars to be mined as input instead of the rather uncertain value of break-even grade $\mathrm{x}(\mathrm{B}) /(1-\mathrm{x}(\mathrm{B}))$ (see Eqns. 2/2A) can be more precise but much more involved in non-linearities (cannot be completely 
linearized) (see, Eqn 10).

\section{REFERENCES}

[1] Ahrens, L.H., 1954, the lognormal distribution of elements, Geochem. et Cosmo. Acta, 5, 49-73; 121-131.

[2] Bear,J., 1972, Dynamics of fluids through porous media, Am. Elsevier, New York, 372p.

[3] Sahu,B. K.,2003, Time series modeling in Earth Sciences, AA Balkema, Lisse, Netherlands, 284p.

[4] Sahu, B.K., 2005, Statistical models in Earth Sciences, BS Publications, Hyderabad, AP, $211 \mathrm{p}$.

[5] Sahu, B.K., 2012, Geology and economics of mining low grade ores, Bull. SGAT, Bhubaneshwar, 13, 72-74.

[6] Sahu, B.K., 2013, Geology applied to sustainable development of mineral resources (Keypaper), Intl. Seminar, Souvenir Volume, ISM Dhanbad, p.77-83.

[7] Sahu, B.K., 2014, Mining and sustainable development of non-renewable mineral resources. Proc. Seminar Sustainable Development of Mineral Resources and Earth Processes, New Delhi, p.4-7.

[8] Sahu, B.K., 2015a, Optimal mining and marketing of lean grade ores, Bull. SGAT, Bhubaneshwar, 16(1):p.1-6.

[9] Sahu, B.K., 2015b, Cutoff grades(assays) modeling for ore extraction: Estimation Theory, Bull.SGAT, Bhubaneshwar, (Ms. 7p (Tables 1-3). Vol 16(2):p.1-7.

[10] Sahu, B.K., 2016, Optimal cutoff grade(assay) in mining for profit maximization. Intl. Conf. Mineral Processing Technology (MPT 2016), PUNE, Jan.2016, 7p. ABS. Vol.(p.100-101). 